\title{
Comparing stage of diagnosis of cervical cancer at presentation in immigrant women and long-term residents of Ontario: a retrospective cohort study
}

\author{
Teja Voruganti MSc, Rahim Moineddin PhD, Nathaniel Jembere MPH, Laurie Elit MD MSC, \\ Eva Grunfeld MD DPhil, Aisha K. Lofters MD PhD
}

\section{Abstract}

Background: Globally, cervical cancer is the fourth most common cancer in women and 7th most common cancer overall. Cervical cancer is highly preventable with screening. Previous work has shown that immigrants are less likely to undergo screening than nonimmigrants in Ontario, Canada. We examined whether immigrant women are more likely to present with later stage cervical cancer than long-term residents of the province.

Methods: We conducted a retrospective matched cohort study of women with cervical cancer diagnosed between 2010 and 2014 using provincial administrative health data. We compared the odds of late-stage diagnosis between immigrants and long-term residents, adjusting for socioeconomic measures, comorbidities and health care use. The outcome of interest was stage of cervical cancer diagnosis, defined as early (stage I) or late (stages II-IV). We confirmed results with a cohort of women with cancer diagnosed between 2007 and 2012.

Results: Complete staging data were available for 218 immigrants and 1348 matched long-term residents. We found no association between immigrant status and stage at diagnosis (adjusted odds ratio [OR] 0.94, 95\% confidence interval [CI] 0.63-1.39). Factors that did show significant association with late-stage diagnosis were physician characteristics, whether a woman had previously undergone screening and had visited a gynecologist in the past 3 years. These results were echoed in the 2007-2012 cohort (immigrants v. long-term residents, OR 0.94, 95\% Cl 0.71-1.20).

Interpretation: Our results show that being an immigrant is not associated with late-stage diagnosis of cervical cancer in Ontario. Programs broadly aimed at immigrants may require a targeted approach to address higher-risk subgroups.

lobally, cervical cancer is the fourth most common cancer in women and seventh most common cancer overall, with age-standardized incidence rates and death rates per 100000 in 2013 nearly twice as high in developing countries as in developed countries (incidence rate 15.70 v. 9.58 ; death rate 8.32 v. 3.96). ${ }^{1,2}$ Differences in incidence can be attributed to widespread implementation of screening programs in developed countries, which make use of the Papanicolaou (Pap) test to detect precancerous changes or cancer. ${ }^{3}$ If preinvasive and early-stage disease is detected, close monitoring and treatment can prevent the progression to invasive cancer. ${ }^{3}$ In Canada, it is estimated that 1500 new cases were diagnosed in 2015, with half of incident cases occurring in Ontario. ${ }^{4}$

In developed countries, such as Canada, where screening programs exist, it is concerning that immigrant women are less likely to undergo screening than nonimmigrants. ${ }^{5,6}$ Although marginalized populations are known to have poorer access to health care resources, recent studies comparing stage at diagnosis among foreign-born versus American-born women have yielded contrasting findings, with 1 study finding that foreign-born women were more likely have their cancer diagnosed at a later stage than nonimmigrant women, and another study that found no difference.,

Given these conflicting results, further exploration of the relationship between immigrant status and stage at diagnosis is warranted. The aim of this study was to examine the association between cervical cancer stage at diagnosis among immigrant women compared with long-term residents of Ontario.

Competing interests: None declared.

This article has been peer reviewed.

Correspondence to: Teja Voruganti, teja.voruganti@mail.utoronto.ca

CMAJ Open 2016. DOI:10.9778/cmajo.20160029 


\section{Methods}

\section{Setting}

Ontario is Canada's most populous province, with a population of 13.8 million people as of $2015 .{ }^{9}$ Census data from 2011 suggest that $28.5 \%$ of Ontarians are immigrants, and the most common regions of origin are South Asia (18.5\%) and China (12.3\%). ${ }^{10}$ In Ontario, coverage of medically necessary services is provided through a government-funded, singlepayer system. Physician services are covered by the Ontario Health Insurance Program, and hospital services are provided for by the Ministry of Health and Long-term Care.

\section{Study design and patient population}

We conducted a retrospective matched cohort study using population-level administrative data that are deidentified and linked through a comprehensive research agreement between the Institute for Clinical Evaluative Sciences (ICES) and the Ontario Ministry of Health and Long-term Care. The cohort consisted of women aged 25 years and older who reside in Ontario and have cervical cancer (ICD 10-CA code C53.X) diagnosed on or after Jan. 1, 2010 until Oct. 1, 2014, and who were eligible for health coverage throughout the study period. We excluded patients with cervical cancer with a recorded hysterectomy before diagnosis, precancerous carcinoma in situ and recurrent cancer.

\section{Outcome}

The primary outcome was stage of cervical cancer stratified into late (II-IV) and early (I) stages. Staging is captured in the Ontario Cancer Registry using best available stage through collaborative staging. This is a process for assigning stage using pathologic data supplemented with clinical data collected across the diagnostic period. An algorithm reconciles stage data acquired from patient health records, generating a best combined stage. ${ }^{11,12}$ Collaborative stage recording began in 2007, and capture of cervical cancer stage with this method became available in 2010. ${ }^{13}$ Data on stage subcategory was not available (e.g., stage IIA v. IIB).

\section{Data sources}

The exposure of interest, immigrant status, was identified from Immigration, Refugees and Citizenship Canada's Permanent Resident Database, which contains demographic, language, place of origin (i.e., country/region of birth) and immigrant class (i.e., economic, family, refugee) information on Ontario permanent residents with a landing visa. The database has been probabilistically linked to the Registered Persons Database for $85.8 \%$ of records. ${ }^{14}$

Cervical cancer diagnosis was obtained from the Ontario Cancer Registry, a passive surveillance patient registry that links data from hospitals, cancer centres and pathology laboratories; incidence data has been previously assessed as having about $92 \%$ completeness. ${ }^{15,16}$

The Ontario Health Insurance Program and Canadian Institute for Health Information Discharge Abstract Database provided information on measures of health care use and comorbidity (using the Johns Hopkins case-mix aggregated diagnosis group and resource utilization bands). ${ }^{17}$

Data on socioeconomic status defined by neighbourhood income quintile and residence type (large urban/small urban/rural), measured with the Rurality Index of Ontario score, were derived from the Registered Persons Database, Postal Code Conversion File and Statistics Canada 2006 Census data.

Physician characteristics have been associated with immigrant screening patterns. ${ }^{18} \mathrm{We}$ obtained family physician sex, whether the family physician was an international medical graduate and whether the physician was part of a patient enrolment model for rostering patients from the ICES Physicians Database and Corporate Physicians Database. HIV status was obtained from the Ontario HIV database.

Linkage of immigrant records to the Registered Persons Database was probabilistic, whereas deterministic linkage of records to all other data sources was done using a secure encrypted ICES number and performed on premises.

This study received ethics approval from the Research Ethics Board of Sunnybrook Health Sciences Centre in Toronto.

\section{Outcome measures}

Immigrants were identified from the Permanent Resident Database, and refer to people who had a landed immigrant or permanent resident status at any time from 1985 to 2014. Long-term residents were defined as those not identified in the Permanent Resident Database. In Canada, immigrants are admitted under 1 of 4 categories: economic class (skilled workers), family class (relatives of Canadian residents), refugees and other (typically accepted for compassionate reasons). ${ }^{19}$ We looked at whether an individual had been screened before and up to 1 year before the date of diagnosis (the prediagnostic interval, during which screening tests are likely diagnostic in nature). Health care use was measured as any visit to a health care provider in the 3 years before the prediagnostic interval, as well as any visit to a gynecologist in the 3 years before the prediagnostic interval. Aggregated diagnosis groups, captured up to 1 year before the date of diagnosis, were stratified into groupings of $0,1-5,6-10,>10$, with higher levels indicating greater comorbidity.

The Ontario government approved a publicly funded, 2 -dose vaccine for human papilloma virus (HPV) types 6, 11, 16 and 18 for girls in grade 8 in 2006 and began implementation through school-based clinics in 2007. ${ }^{20}$ Because HPV is the cause of most cervical cancers, ${ }^{21}$ we restricted the cohort to women aged 25 and older who were less likely to have received the vaccine. However, girls have the choice to opt out of the program, and those who are not eligible for the program could pay for vaccination out of pocket for a cost of around $\$ 400$.

\section{Statistical analysis}

Immigrants were matched in a 1 to 4 ratio to long-term residents aged up to 5 years older or younger at date of diagnosis, and on census tract. For descriptive analysis, we report percentages for categorical data, and means and standard devia- 
tions for continuous data. Bivariate and multivariate conditional logistic regressions were used to determine odds ratios (ORs) with 95\% confidence intervals (CIs) for late-stage cervical cancer for immigrants versus long-term matched residents. The aforementioned variables (see Data sources) were included in the model because of evidence of clinical meaningfulness. ${ }^{5,18,22,23}$ Screening status was excluded from the model because it is theoretically on the causal pathway.

Based on incidence data that about $45 \%$ of cervical cancer cases are late stage, ${ }^{4}$ and that about $30 \%$ of the Ontario population consists of immigrants, a projected sample size was calculated. Assuming a power of $80 \%$, a statistical significance level of $5 \%$, and matching immigrants to long-term residents in a ratio of 1 to 4 , we needed 261 immigrants matched to 1044 long-term residents to detect a difference of $10 \%$ or larger on stage at diagnosis. We used SAS 9.3 to perform the analyses. All cell sizes of fewer than 5 women were suppressed. We report $p$ values less than 0.05 as significant. A confirmatory analysis was done with a cohort of women from 2007 to 2012.

\section{Results}

Before matching, our study sample consisted of 2508 women (Figure 1), 345 (13.7\%) of whom were immigrants. In comparison, $25 \%-26 \%$ of women aged 25 years and older in Ontario are foreign-born. ${ }^{10,24}$ Immigrant women were matched on age at diagnosis and census tract with 1380 longterm residents. Characteristics of the final study cohort are presented in Table 1.

Table 2 describes the characteristics of the 345 immigrant women in the study cohort, stratified by stage at diagnosis. Most of the immigrants with a diagnosis of cervical cancer were from East Asia (34.2\%), Western Europe and the USA (27.2\%), and South Asia (13.9\%). Women of East Asian or Western European and American origin had a higher incidence of early stage cancer, whereas the incidence of latestage cancer in South Asian women was higher.

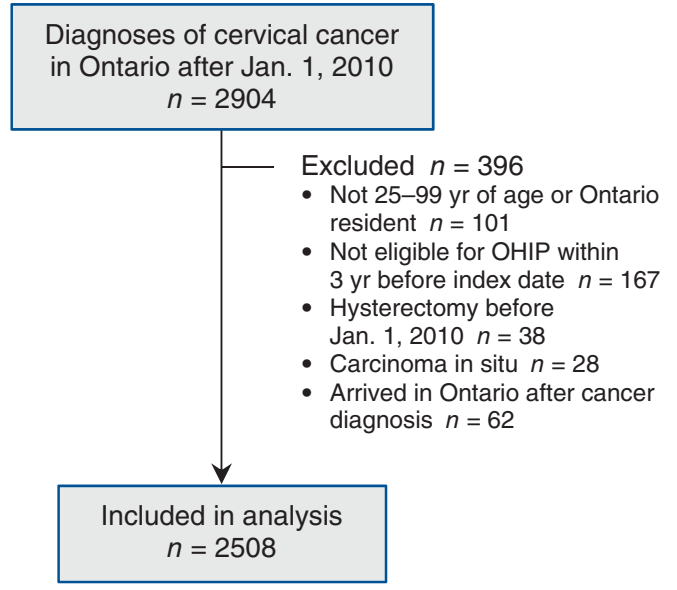

Figure 1: Selection of study cohort.
Regarding stage at diagnosis, among immigrants, $34.2 \%$ of cancers were diagnosed at stage I, $12.4 \%$ at stage II, $9.8 \%$ at stage III and $6.7 \%$ at stage IV. Among long-term residents, $33.5 \%$ of cancers were diagnosed at stage I, $10.2 \%$ at stage II, $11.8 \%$ at stage III and $7.7 \%$ at stage IV. Stage data were not available for $36.8 \%$ of immigrants and for $36.7 \%$ of longterm residents. A confirmatory cohort with greater availability of stage data showed comparable results; stage data were not available for $13.5 \%$ of immigrants and $14.4 \%$ of long-term residents (results not shown).

We did not observe a difference in screening history between immigrants and long-term residents in our cohort of women who already had a diagnosis of cervical cancer. There was no difference between immigrants and long-term residents with cervical cancer on stage when stratified by screening status. In addition, we did not see an income gradient or difference in comorbidity or residence type between immigrants or long-term residents with cervical cancer.

The unadjusted and adjusted ORs for the outcome of late vs. early stage cervical cancer at the time of diagnosis are presented in Table 3. No significant difference in diagnosis of late-stage cancer was seen between immigrants and long-term residents (unadjusted OR 0.99, 95\% CI $=0.70-1.40$; adjusted OR $0.94,95 \% \mathrm{CI}=0.63-1.39)$. In bivariate analyses, significant associations were seen with comorbidity, screening status, gynecologist visit, sex of family physician and number of health care contacts in the past 3 years, but only history of a gynecologist visit in the prediagnostic interval remained significant in the adjusted model. HIV status was excluded from the model because there were too few cases, and screening status was excluded because lack of screening could be on the causal pathway.

\section{Interpretation}

Our results show no association between immigrant status and stage of diagnosis of cervical cancer in Ontario from 2010 to 2014. These results were replicated with data from 2007 to 2012 to confirm that the observed lack of association was not due to data unavailability.

Our findings present a thought-provoking query as to why, despite having lower screening rates for cervical cancer than long-term residents, ${ }^{25}$ immigrant women in Ontario did not present with more advanced disease. Risk factors for cervical cancer include HPV infection (which is sexually transmitted) and smoking, and it is reasonable to suggest that Ontario's immigrant population may have a different prevalence of these risk factors. Compared with the difference in screening rates between immigrants and long-term residents in the general population, the lack of observed difference in our cohort of women with a cervical cancer diagnosis may be a positive indication that the benefit of screening is of equal value to both immigrants and long-term residents.

We observed a higher incidence of later stage cancer in South Asian women. In previous work, South Asian women showed the lowest rates of screening among immigrant women in Ontario. ${ }^{5}$ Furthermore, it was shown that South 
Table 1: Characteristics of women in the study cohort with cervical cancer diagnosed in Ontario in 2010-2014

\begin{tabular}{|c|c|c|c|}
\hline \multirow[b]{2}{*}{ Characteristic } & \multicolumn{3}{|c|}{ No. $(\%)^{*}$} \\
\hline & Immigrants $(n=345)$ & $\begin{array}{l}\text { Long-term residents } \\
\qquad(n=1380)\end{array}$ & $\begin{array}{c}\text { Standardized mean } \\
\text { difference } \dagger\end{array}$ \\
\hline Age, $y r$, mean $\pm S D$ & $52 \pm 14.7$ & $52 \pm 14.7$ & 0.03 \\
\hline \multicolumn{4}{|l|}{ Neighbourhood income quintile } \\
\hline 1 (lowest) & $96(27.8)$ & $304(22.0)$ & 0.3 \\
\hline 2 & $93(27.0)$ & $271(19.6)$ & \\
\hline 3 & $47(13.6)$ & $278(20.1)$ & \\
\hline 4 & $64(18.6)$ & $271(19.6)$ & \\
\hline 5 (highest) & $44(12.8)$ & $247(17.9)$ & \\
\hline Missing data & $<5(\mathrm{NA})$ & $<5(\mathrm{NA})$ & \\
\hline \multicolumn{4}{|l|}{ Rurality index } \\
\hline Major urban & $332(96.0)$ & 937 (67.9) & 0.9 \\
\hline Nonmajor urban & $<5(\mathrm{NA})$ & $324(23.5)$ & \\
\hline Rural & $<5(\mathrm{NA})$ & $108(7.8)$ & \\
\hline Missing data & $<5(\mathrm{NA})$ & $8(0.6)$ & \\
\hline \multicolumn{4}{|l|}{ Aggregated diagnosis group } \\
\hline 0 (no comorbidity) & $23(6.7)$ & $108(7.8)$ & 0.1 \\
\hline $1-5$ & $163(47.2)$ & $655(47.4)$ & \\
\hline $6-9$ & $105(30.4)$ & $445(32.2)$ & \\
\hline$\geq 10$ (high comorbidity) & $54(15.7)$ & $172(12.5)$ & \\
\hline \multicolumn{4}{|l|}{ Time since last screening, $y r$} \\
\hline$>3$ & $126(36.5)$ & $465(33.7)$ & 0.1 \\
\hline $3-5$ & $32(9.3)$ & $162(11.7)$ & \\
\hline$>5$ & $11(3.2)$ & $38(2.8)$ & \\
\hline Never screened & $174(50.4)$ & $715(51.8)$ & \\
\hline \multicolumn{4}{|l|}{ Visit to gynecologist in past $3 \mathrm{yr}$} \\
\hline Yes & $204(59.1)$ & $788(57.1)$ & 0.04 \\
\hline No & $141(40.9)$ & $592(42.9)$ & \\
\hline Missing data & - & - & \\
\hline No. of health contacts in past $3 \mathrm{yr}$, mean $\pm \mathrm{SD}$ & $30.7 \pm 25.3$ & $29.0 \pm 30.3$ & 0.05 \\
\hline Diagnosis of HIV & $<5(\mathrm{NA})$ & $<5(\mathrm{NA})$ & - \\
\hline \multicolumn{4}{|l|}{ Family physician sex } \\
\hline Female & $118(34.2)$ & $507(36.7)$ & 0.2 \\
\hline Male & $222(64.3)$ & $798(57.8)$ & \\
\hline Missing data & $6(1.7)$ & $64(4.6)$ & \\
\hline \multicolumn{4}{|l|}{$\begin{array}{l}\text { Family physician is an international medical } \\
\text { graduate }\end{array}$} \\
\hline Yes & $154(44.6)$ & $250(18.1)$ & 0.6 \\
\hline No & $186(53.9)$ & $1066(77.2)$ & \\
\hline Missing data & $6(1.7)$ & $64(4.6)$ & \\
\hline \multicolumn{4}{|l|}{ Family physician in a patient enrollment model } \\
\hline Yes & $296(85.8)$ & $1207(87.5)$ & 0.3 \\
\hline No & $45(13.0)$ & $112(8.1)$ & \\
\hline Missing data & $<5(\mathrm{NA})$ & $61(4.4)$ & \\
\hline $\begin{array}{l}\text { Note: } N A=\text { not available. } \\
\text { *Unless otherwise specified. } \\
\text { †Values }>0.1 \text { are considered important differences. }\end{array}$ & & & \\
\hline
\end{tabular}




\section{OPEN}

Research

Table 2: Characteristics of immigrant women in Ontario with a diagnosis of cervical cancer

\begin{tabular}{|c|c|c|c|c|}
\hline \multirow[b]{2}{*}{ Characteristic } & \multicolumn{4}{|c|}{$\begin{array}{l}\text { Cervical cancer, no. (\%) } \\
\qquad n=345\end{array}$} \\
\hline & Overall & No known stage & Early stage & Late stage \\
\hline \multicolumn{5}{|l|}{ Immigrant class } \\
\hline Economic & $134(38.8)$ & $43(33.9)$ & $55(46.6)$ & $36(36.0)$ \\
\hline Family & $162(47.0)$ & $64(50.4)$ & $45(38.1)$ & $53(53.0)$ \\
\hline Refugee with landing visa & $48(13.9)$ & $19(15.0)$ & $18(15.3)$ & $11(11.0)$ \\
\hline Other & $<5(\mathrm{NA})$ & $<5(\mathrm{NA})$ & - & - \\
\hline \multicolumn{5}{|l|}{ Language ability } \\
\hline English or French & $195(56.5)$ & $75(59.1)$ & $71(60.2)$ & $49(49.0)$ \\
\hline Other & $150(43.5)$ & $52(40.9)$ & $47(39.8)$ & $51(51.0)$ \\
\hline \multicolumn{5}{|l|}{ Region of origin } \\
\hline Africa & $8(2.3)$ & $<5(\mathrm{NA})$ & $6(5.1)$ & $<5$ (NA) \\
\hline Caribbean & $26(7.5)$ & $11(8.7)$ & $9(7.6)$ & $6(6.0)$ \\
\hline East Asia & $117(34.2)$ & $40(31.5)$ & $46(39.0)$ & $31(31.0)$ \\
\hline Latin America & $29(8.4)$ & $10(7.9)$ & $11(9.3)$ & $8(8.0)$ \\
\hline Middle East & $20(5.8)$ & $12(9.4)$ & $<5(\mathrm{NA})$ & $<5(\mathrm{NA})$ \\
\hline South Asia & $48(13.9)$ & $22(17.3)$ & $<5(\mathrm{NA})$ & $22(22.0)$ \\
\hline Western Europe and USA & 94 (27.2) & $30(23.6)$ & $36(30.5)$ & $28(28.0)$ \\
\hline
\end{tabular}

Asian women in Ontario are more likely to present with late stage breast cancer. ${ }^{26}$ These trends may indicate causes related to sociocultural determinants of health associated with place of origin, including religious and cultural beliefs influencing how and when health care is accessed. ${ }^{27-29}$

Our finding that physician characteristics were related to stage at diagnosis may be due to female patients feeling more comfortable with female health care providers. It has been previously reported that physicians who were international medical graduates screened for cervical cancer at lower rates than Canadian graduates ${ }^{18}$ here, we found that immigrants were more likely to have a family physician who is an international medical graduate, but we still did not see a difference in stage at presentation.

Similar overall findings were shown by Gomez and colleagues using data from the California Cancer Registry to compare foreign-born and American-born women of Hispanic origin on the odds of late stage cervical cancer (OR $1.04,95 \%$ CI 0.94-1.15). Montealegre and colleagues, however, used data from the Surveillance, Epidemiology, and End Results program, and found that foreign-born Hispanic women were slightly more likely to have a late-stage diagnosis than US-born Hispanic women (OR 1.09, 95\% CI 1.05$1.15)$, although the outcome was defined differently than was done in the present study. ${ }^{8}$ It was suggested that immigrants may be selectively healthier than nonimmigrants at immigration and have a different profile of risk factors that protects against last-stage diagnosis.

\section{Limitations}

Here, we are reporting findings based on the entire population of the province of Ontario. However, our study has several limitations. Our data set was not sufficiently large to allow for subgroup comparisons, including between more recent and less recent immigrants. In addition, the transition to new staging methods resulted in a sizeable proportion (36\%) of unavailable stage data in the 2010-2014 cohort, although the comparable proportion of missing data between both groups makes it unlikely to be an issue of differential reporting. We confirmed our results with data from 2007 to 2012, for which the proportion of missing data was smaller (14\%).

The Immigration, Refugees and Citizenship Canada's Permanent Resident Database does not capture all immigrants to Ontario (e.g., those who migrated to another province before coming to Ontario), and thus our control group likely includes some foreign-born women. In addition, the collaborative staging data from the Ontario Cancer Registry, to our knowledge, has not been validated.

Finally, not all relevant variables are captured in administrative data, including those such as educational achievement and religion, and variables such as country of origin may not accurately reflect sociocultural influences on disease risk factors at an individual level. Although our results are representative of the population of Ontario, they may not be generalizable to other regions with different population demographics. 


\begin{tabular}{|c|c|c|c|c|}
\hline Characteristic & Unadjusted OR $(95 \% \mathrm{Cl})$ & $p$ value & Adjusted OR (95\% Cl) & $p$ value \\
\hline \multicolumn{5}{|l|}{ Immigrant status } \\
\hline Long-term resident & $0.99(0.70-1.40)$ & \multirow[t]{2}{*}{0.9} & $0.94(0.63-1.39)$ & \multirow[t]{2}{*}{0.7} \\
\hline Immigrant & 1.00 & & 1.00 & \\
\hline \multicolumn{5}{|l|}{ Income quintile } \\
\hline 1 (lowest) & $0.85(0.54-1.36)$ & \multirow[t]{5}{*}{0.8} & $0.87(0.53-1.43)$ & \multirow[t]{5}{*}{0.6} \\
\hline 2 & $1.02(0.62-1.67)$ & & $0.99(0.58-1.70)$ & \\
\hline 3 & $0.86(0.53-1.41)$ & & $0.92(0.54-1.58)$ & \\
\hline 4 & $1.05(0.64-1.73)$ & & $1.33(0.78-2.27)$ & \\
\hline 5 (highest) & 1.00 & & 1.00 & \\
\hline \multicolumn{5}{|l|}{ Rurality index } \\
\hline Rural & $0.98(0.53-1.80)$ & \multirow[t]{3}{*}{$<1.0$} & $0.94(0.45-1.93)$ & \multirow[t]{3}{*}{0.7} \\
\hline Nonmajor urban & $0.95(0.67-1.38)$ & & $0.85(0.55-1.30)$ & \\
\hline Major urban & 1.00 & & 1.00 & \\
\hline \multicolumn{5}{|l|}{ Aggregated diagnosis group } \\
\hline 0 (no comorbidity) & $3.29(1.51-7.15)$ & \multirow[t]{4}{*}{0.0006} & $1.66(0.60-4.59)$ & \multirow[t]{4}{*}{0.2} \\
\hline $1-5$ & $1.50(0.93-2.43)$ & & $1.18(0.61-2.27)$ & \\
\hline $6-9$ & $0.88(0.52-1.48)$ & & $0.78(0.42-1.45)$ & \\
\hline$\geq 10$ (high comorbidity) & 1.00 & & 1.00 & \\
\hline \multicolumn{5}{|l|}{ Time since last screening, $\mathrm{yr}^{*}$} \\
\hline$>3$ & $0.41(0.29-0.59)$ & \multirow[t]{4}{*}{$<0.0001$} & \multirow[t]{4}{*}{-} & \multirow[t]{4}{*}{-} \\
\hline $3-5$ & $0.48(0.28-0.81)$ & & & \\
\hline$>5$ & $1.88(0.54-6.54)$ & & & \\
\hline Never screened & 1.00 & & & \\
\hline \multicolumn{5}{|l|}{ Visit to gynecologist in the past $3 \mathrm{yr}$} \\
\hline No & $2.73(2.00-3.73)$ & \multirow[t]{2}{*}{$<0.0001$} & $2.47(1.8-3.50)$ & \multirow[t]{2}{*}{$<0.0001$} \\
\hline Yes & 1.00 & & 1.00 & \\
\hline \multicolumn{5}{|l|}{ Family physician sex } \\
\hline Female & $0.69(0.50-0.95)$ & \multirow[t]{2}{*}{0.02} & $0.71(0.50-1.00)$ & \multirow[t]{2}{*}{0.06} \\
\hline Male & 1.00 & & 1.00 & \\
\hline \multicolumn{5}{|l|}{$\begin{array}{l}\text { Family physician in a patient enrolment } \\
\text { model }\end{array}$} \\
\hline No & $1.65(0.99-2.77)$ & \multirow[t]{2}{*}{0.06} & $1.72(0.98-3.00)$ & \multirow[t]{2}{*}{0.06} \\
\hline Yes & 1.00 & & 1.00 & \\
\hline No. of health care contacts in past $3 \mathrm{yr}$ & $0.99(0.97-1.00)$ & 0.01 & $1.00(0.99-1.01)$ & 0.9 \\
\hline
\end{tabular}

\section{Conclusion}

We observed no difference in stage at diagnosis between immigrants and long-term residents with cervical cancer in Ontario. In the context of previous research showing that immigrant women had lower rates of screening for cervical cancer, our results represent an unexpected finding that sug- gests that previously broad notions regarding immigrant health may require a refined approach that factors in differing innate health risks by ethnic group and health habits. Future work into the characteristics of those patients who never undergo screening will better elucidate how programs may be directed to address an otherwise preventable disease. 


\section{References}

1. Ferlay J, Soerjomataram I, Dikshit R, et al. Cancer incidence and mortality worldwide: sources, methods and major patterns in GLOBOCAN 2012. Int 7 Cancer 2015;136:E359-86.

2. Fitzmaurice C, Dicker D, Pain A, et al. The global burden of cancer 2013. $7 A M A$ Oncol 2015;1:505-27.

3. Murphy J, Kennedy EB, Dunn S, et al. Cervical screening: a guideline for clinical practice in Ontario. 7 Obstet Gynaecol Can 2012;34:453-8.

4. Canadian Cancer Statistics 2015. Toronto: Canadian Cancer Society; 2015.

5. Lofters AK, Moineddin R, Hwang SW, et al. Predictors of low cervical cancer screening among immigrant women in Ontario, Canada. BMC Womens Health 2011;11:20.

6. De Alba I, Hubbell FA, McMullin JM, et al. Impact of US citizenship status on cancer screening among immigrant women. 7 Gen Intern Med 2005;20:290-6.

7. Gomez N, Guendelman S, Harley KG, et al. Nativity and neighborhood characteristics and cervical cancer stage at diagnosis and survival outcomes among Hispanic women in California. Am 7 Public Health 2015; 105:538-45.

8. Montealegre JR, Zhou R, Amirian ES, et al. Nativity disparities in late-stage diagnosis and cause-specific survival among Hispanic women with invasive cervical cancer: an analysis of surveillance, epidemiology, and end results data. cancer causes \& control. Cancer Causes Control 2013;24:1985-94.

9. Population by year, by province and territory. Ottawa: Statistics Canada; 2015.

10. 2011 National Household Survey. Ottawa: Statistics Canada; 2011.

11. Edge S, Byrd D, Compton C, et al. Collaborative Staging Manual and Coding Instructions, version 02.05. Bethesda (MD): Collaborative Staging Task Force of the American Joint Committee on Cancer; 2010.

12. Guidelines for staging patients with cancer. Toronto: Cancer Care Ontario; 2005.

13. Reporting of cancer stage information by acute care hospitals in Ontario [Cancer Care Ontario internal documentation]. Toronto: Cancer Care Ontario; 2012.

14. Initial validation of Citizenship and Immigration Canada (CIC) Database with the Registered Persons Database (RPDB) at ICES. Toronto: Institute for Clinical Evaluative Sciences (ICES); 2010.

15. Marrett LD, Clarke EA, Hatcher J, et al. Epidemiologic research using the Ontario Cancer Registry. Can 7 Public Health 1986;(Suppl 1);24:79-85.

16. Robles SC, Marrett L, Clarke E, et al. An application of capture-recapture methods to the estimation of completeness of cancer registration. 7 Clin Epidemiol 1988;41:495-501.

17. Weiner JP. The Johns Hopkins ACG® Case-Mix System Version 6.0 Release Notes. Baltimore (MD): The Johns Hopkins University Bloomberg School of Public Health, Health Services Research \& Development Center: The Johns Hopkins University; 2003.

18. Lofters AK, Ng R, Lobb R. Primary care physician characteristics associated with cancer screening: a retrospective cohort study in Ontario, Canada. Cancer Med 2015;4:212-23.

19. Immigration and Refugee Protection Act. (S.C. 2001, c. 27). Available: http://laws justice.gc.ca/eng/acts/I-2.5/ (accessed 2016 Feb. 2)

20. Ontario's HPV vaccination program. Toronto: Ministry of Health and Long-Term Care; 2016.

21. Human papillomaviruses. IARC monographs on the evaluation of carcinogenic risks to humans. Lyon (FR): International Agency for Research on Cancer; 2005

22. Booth CM, Li G, Zhang-Salomons J, et al. The impact of socioeconomic status on stage of cancer at diagnosis and survival: a population-based study in Ontario, Canada. Cancer 2010;116:4160-7.

23. Elit L, Krzyzanowska M, Saskin R, et al. Sociodemographic factors associated with cervical cancer screening and follow-up of abnormal results. Can Fam Physician 2012;58:e22-31.

24. 2006 Census. Ottawa: Statistics Canada; 2006.

25. Lofters AK, Moineddin R, Hwang SW, et al. Low rates of cervical cancer screen- ing among urban immigrants: a population-based study in Ontario, Canada. Med Care 2010;48:611-8.

26. Ginsburg OM, Fischer HD, Shah BR, et al. A population-based study of ethnicity and breast cancer stage at diagnosis in Ontario. Curr Oncol 2015;22:97-104.

27. Crawford J, Ahmad F, Beaton D, et al. Cancer screening behaviours among South Asian immigrants in the UK, US and Canada: a scoping study. Health Soc Care Community 2016;24:123-53.

28. Gupta A, Kumar A, Stewart DE. Cervical cancer screening among South Asian women in Canada: the role of education and acculturation. Health Care Women Int 2002;23:123-34

29. Redwood-Campbell L, Fowler N, Laryea S, et al. 'Before you teach me, I cannot know': immigrant women's barriers and enablers with regard to cervical cancer screening among different ethnolinguistic groups in Canada. Can $\mathcal{F}$ Public Health 2011;102:230-4.

Affiliations: Institute of Health Policy, Management and Evaluation (Voruganti, Moineddin, Grunfeld); Department of Family and Community Medicine (Moineddin, Grunfeld, Lofters), University of Toronto; Institute of Clinical Evaluative Sciences (Moineddin, Jembere, Lofters), Toronto, Ont.; Department of Obstetrics and Gynecology (Elit), McMaster University, Hamilton, Ont.; Ontario Institute for Cancer Research (Grunfeld), Toronto, Ont.; Centre for Research on Inner City Health, Li Ka Shing Knowledge Institute (Lofters), St. Michaels Hospital, Toronto, Ont.

Contributors: Teja Voruganti conceived of the study, contributed to the design of the study and analysis, and wrote the first draft of the article. Rahim Moineddin contributed to the design and analysis of the study and provided feedback on the manuscript. Nathaniel Jembere performed the analysis of the study and provided feedback on the manuscript. Laurie Elit helped conceive the study, contributed to writing the manuscript and provided feedback. Eva Grunfeld helped conceive the study, contributed to writing the manuscript and provided feedback. Aisha K. Lofters helped conceive the study, contributed to the design and analysis of the study, and provided feedback on the manuscript. All authors gave final approval of the version to be published and are willing to act as guarantors of this work.

Acknowledgments: Teja Voruganti is supported by a grant from the Canadian Institutes for Health Research $\mathrm{MD} / \mathrm{PhD}$ studentship and a McLaughlin Foundation fellowship. Eva Grunfeld is supported by a clinician scientist award from the Ontario Institute for Cancer Research (OICR). Aisha Lofters is supported by a Career Development Award in Cancer Prevention from the Canadian Cancer Society Research Institute and as a clinician scientist at the Department of Family and Community Medicine at the University of Toronto. Data were provided by Citizenship and Immigration Canada, the Ontario Cancer Registry and the Institute for Clinical Evaluation Sciences (ICES). ICES is supported by a grant from the Ontario Ministry of Health and Long Term Care (MOHLTC). The opinions and conclusions expressed here are those of the authors and not of the supporting organizations (ICES, OICR, MOHLTC).

Supplemental information: For reviewer comments and the original submission of this manuscript, please see www.cmajopen.ca/content/4/3/ E424/suppl/DC1 